\title{
Homicídio de mulheres: pesquisa e proposta de intervenção de Eva Alterman Blay
}

\section{Assassinato de mulheres e Direitos Humanos.}

BLAY, Eva Alterman.

São Paulo: Ed. 34, 2008. 248 p.
O livro Assassinato de mulheres e Direitos Humanos, da socióloga Eva A. Blay, apresenta a extensa pesquisa feita pela autora e por sua equipe. Com relação aos julgamentos de tentativas ou homicídios de mulheres, a autora questiona: "Será que nada mudou na passagem dos séculos XX para o XXI?" (p. 22). Sua pesquisa buscou entender o contexto de violências contra mulheres que resultam em mortes.

A pesquisa teve três focos objetivos: pesquisar os tipos de tentativa ou homicídio em que as mulheres são vítimas; pesquisar os homicídios ou tentativas em todas as faixas etárias; propor políticas públicas transversais que atuem no aspecto de hierarquia de gênero. Desde o início do livro, percebe-se a preocupação da autora com a intervenção no sentido de não apenas investigar, levantar informações ou teorizar, mas também de propor possíveis ações preventivas para evitar a violência contra mulheres. Trata-se de assunto pertinente, já que atualmente há inúmeras discussões sobre a Lei 11.340 (para coibir a violência doméstica e intrafamiliar contra mulheres) e a implementação de políticas públicas que não fiquem apenas na punição aos/às autores/as de violência.
No primeiro capítulo, intitulado "O silêncio dos dados", Blay apresenta a dificuldade para coletar as informações sobre crimes contra muIheres. Ela fez a pesquisa em materiais veiculados em imprensa escrita, programas de rádio, internet e televisão (de 1991 até 2000, casos brasileiros e estrangeiros); Boletins de Ocorrência (BOs) que foram registrados em delegacias da cidade de São Paulo no ano de 1998; amostra quantitativa de processos criminais de cinco Fóruns de Júri da Comarca de São Paulo de 1997; entrevistas com operadores de Direito.

"Rádio, televisão, Internet e ensino do Direito" é o título do segundo capítulo, que se inicia com a afirmação da autora de que no imaginário brasileiro as agressões às mulheres sempre estiveram presentes, o que ela exemplifica com a letra da antiga música "Cabocla Teresa", de Raul Torres e João Pacífico, fazendo, assim, uma reflexão sobre a importância de uma mudança nos valores sociais. Blay retoma historicamente os casos de assassinatos de mulheres por seus cônjuges (incluindo casos do século XIX), com a justificativa utilizada frequentemente de que "foi por amor" ou "legítima defesa da honra", e relembra antigas discussões sobre os chamados "crimes de paixão", durante as campanhas contra a "epidemia" desse tipo de assassinato desde os anos 20/30. A autora também questiona a mensagem indireta, nos anos 60 e 70, de que em crimes com alegação de "forte emoção" os autores não devam ser punidos. "A vítima era a autora de sua própria morte" (p. 43), argumento de defesa utilizado por muitos advogados nos "crimes de paixão", como o conhecido caso de Doca Street no 
assassinato de sua companheira Ângela Diniz. O advogado de Doca, Evandro Lins e Silva, escreveu livros que ensinavam táticas de defesa explorando a contraposição da "personalidade" e da conduta do réu e da vítima, em que a máxima era: a vítima fez de tudo para ser morta.

A campanha feminista "Quem ama não mata!", de 1979, retomou as reivindicações dos anos 20 e 30 contra os crimes "por amor". Em toda a discussão tumultuada da época, as feministas exigiam Direitos Humanos para as mulheres. Blay nota que, após esses protestos e a condenação de Doca Street, iniciou-se uma mudança na forma de ver esses crimes. A autora continua questionando por que, ao mudarem os valores, mesmo assim são frequentes os assassinatos de mulheres.

No capítulo 3 , sobre "Os jornais na passagem para o século XXI", Blay dedica-se à apresentação do que foi coletado na pesquisa em materiais de mídia. Relata que, até meados dos anos 80 , a violência contra mulheres era noticiada como um fato qualquer, em frequentes alusões de que a vítima merecia o que sofreu. Também violências como incesto e estupro eram muitas vezes estampadas como não violência. A mudança desse enfoque começa nos anos 90 e se estende pela primeira década dos anos 2000 , quando a imprensa deixou de culpabilizar as mulheres por sua morte e passou a questionar as justificativas dos homicídios contra mulheres, ou seja, passou a ser investigativa, neutra e problematizadora. Blay ressalta a importância dos movimentos feministas (questionando os valores sociais) para a mudança da linguagem da imprensa e lamenta que, apesar da criação das Delegacias de Defesa da Mulher (facilitando a denúncia), "estupros e mortes continuam a ocorrer" (p. 58).

Nota-se que aumentou o número de notícias sobre crimes contra mulheres, o que revela que a opinião pública está reagindo, não aceitando, esse tipo de delito. "Na virada para o século XXI, diferentemente dos anteriores, o noticiário sobre a violência contra a mulher se torna cada vez mais numeroso e a mídia revela certa demanda social para a descoberta e punição dos assassinos, embora resistam casos noticiados sob uma ótica conservadora e machista" (p. 67). A autora deixa claro ao longo do livro sua militância feminista, fazendo reflexões sobre a dominação masculina, por vezes em tom de denúncia.

Nessa etapa da pesquisa, além de serem analisadas brevemente manchetes e reportagens, foram classificados os perfis de vítimas e acusados/as de homicídios ou tentativas contra mulheres e os motivos alegados, entre os quais, em primeiro lugar, a proliferação da violência urbana, e, em segundo, a suspeita de adultério, ciúmes ou separação. Blay reforça a ideia de que os valores culturais das relações assimétricas de gênero permeiam os motivos dos assassinatos.

No quarto capítulo do livro, com o título "A polícia e o assassinato de mulheres", a autora descreve o que foi pesquisado nos BOs, apresentando estatísticas sobre os perfis das vítimas e dos/as autores/as dos crimes (faixa etária, etnia, profissão, situação socioeconômica, formação escolar e relação entre vítima e autor/a do crime) e espécies de instrumentos utilizados para a agressão.

"Réus e vítimas na justiça" é o título do quinto capítulo, que apresenta as informações coletadas nos processos criminais investigados na pesquisa. Blay explica didaticamente os trâmites do processo criminal, da denúncia até o Júri, com o respectivo veredicto. Apresenta estatísticas sobre perfis de vítimas e acusados/as e o relacionamento entre estes e aquelas e conclui que as informações coletadas nos processos criminais são mais precisas do que as dos BOs e dos jornais. Segundo a autora, assassinatos de mulheres não ocorrem apenas no ambiente doméstico, mas também no extradomiciliar, porque há uma dominação masculina nos diversos espaços em que as mulheres transitam, trabalham, estudam, realizam suas atividades cotidianas.

Blay continua buscando quebrar estereótipos no sexto capítulo, sobre "A Justiça e o Tribunal de Júri", esclarecendo que "a imagem negativa do Judiciário resulta da falta de conhecimento que a sociedade tem do complexo percurso da Justiça" (p. 131), daí as afirmações populares sobre lentidão, penalização branda, diferença de pena para diferentes camadas sociais, entre outras. A autora propõe soluções para um sistema judiciário mais eficaz, com redução da burocracia e do número de recursos, controle da presença de advogados, legislação mais restritiva, entre outras sugestões. Para embasar suas propostas, reproduz "monotonamente", como ela mesma considera, trechos de processos e veredictos de Júris, exemplificando a complexidade e as dificuldades dos trâmites judiciais.

O último capítulo traz as considerações finais, em que a autora explana sobre culturas aprendidas e reproduzidas nas relações sociais de gênero que, combinadas a uma cultura de 
violência, podem resultar na morte de mulheres, independentemente de camada social, raça/ etnia ou geração. Blay ressalva que apenas a categoria "violência doméstica" não dá conta de todos os casos de tentativas ou homicídios de mulheres. Para uma mudança desse quadro, é necessária uma modificação de valores e de cultura.

Blay reconhece que houve mudança resultante das denúncias e protestos de escritoras, jornalistas, feministas e intelectuais contra crimes que ficaram impunes. As alegações de "defesa da honra" e "forte emoção" não mais livram os/ as autores/as de crimes da punição. Em todo o livro a autora se questiona como ainda é grande o número de casos, mesmo com a visibilidade que a violência contra mulheres ganhou ao longo do tempo.

No livro questões jurídicas tiveram um enfoque sociológico e feminista da autora, que discutiu uma realidade de violência de gênero ainda presente, o que podemos ver diariamente veiculado na mídia, apesar da vigência da Lei 11.340 .

A autora não se atém à Lei 11.340 , sobre a qual faz um comentário en passant na conclusão e uma breve explicação em anexo. A Lei tenta coibir a violência doméstica, mas não fez cessar as ocorrências. Esse fato é muito questionado pela autora, que no livro deixa uma permanente questão: se os valores mudam constantemente, por que os assassinatos continuam ocorrendo?

Direitos Humanos também não é um assunto que a autora explora com profundidade, apesar de estar referido no título do livro. As leis de proteção contra mulheres só foram criadas em um contexto de Direitos Humanos. A primeira forma desses direitos foi a Declaração Universal dos Direitos do Homem de 1948, aprovada por 48 países. Atualmente mais de cem países adotam os direitos humanos, sendo portanto legitimado em diversos povos. Mas a diferenciação de gênero só apareceu nos anos 1980.

Apesar de a autora não se aprofundar na temática de Direitos Humanos e da Lei 11.340 , isso não afeta a qualidade da obra de Eva $A$. Blay, fundada em pesquisa desenvolvida em um longo tempo e árduo trabalho. Trata-se de um livro que amplia a visão sobre violência contra mulheres com informações sobre o contexto de homicídios contra elas.

No livro resenhado, Eva Blay retrata principalmente as relações de gênero, mas também discute continuamente toda uma realidade brasileira em diferentes camadas sociais, comentando sobre racismo, precariedade nas condições de vida e nos serviços públicos, valores sociais preconceituosos, violências urbanas, entre outros temas.

\section{Nota}

' Lilia Blima SCHAIBER et al., 2005.

\section{Referência bibliográfica}

SCHAIBER, Lilia Blima et al. Violência dói e não é direito: a violência contra a mulher, a saúde e os direitos humanos. São Paulo: Ed. UNESP, 2005.

Maria Eduarda Ramos Universidade Federal de Santa Catarina 